\title{
Monitoring colony phenology using within-day variability in continuous weight and temperature of honey bee hives
}

\author{
W. G. Meikle ${ }^{1}$, M. Weiss ${ }^{1}$, A. R. Stilwell ${ }^{1,2}$ \\ ${ }^{1}$ Carl Hayden Bee Research Center, USDA-ARS, 2000 E. Allen Road, Tucson, AZ 85719, USA \\ ${ }^{2}$ USDA APHIS PPQ, 5940 S. 58th St., Lincoln, NE 68516, USA
}

Received 18 January 2015 - Revised 7 April 2015 - Accepted 23 April 2015

\begin{abstract}
Continuous weight and temperature data were collected for honey bee hives in two locations in Arizona, and those data were evaluated with respect to separate measurements of hive phenology to develop methods for noninvasive hive monitoring. Weight and temperature data were divided into the $25-\mathrm{h}$ running average and the daily within-day changes, or "detrended" data. Data on adult bee and brood masses from hive evaluations were regressed on the amplitudes of sine curves fit to the detrended data. Weight data amplitudes were significantly correlated with adult bee populations during nectar flows, and temperature amplitudes were found inversely correlated with the log of colony brood weight. The relationships were validated using independent datasets. In addition, the effects of an adult bee kill on hive weight data were contrasted with published data on weight changes during swarming. Continuous data were found to be rich sources of information about colony health and activity.
\end{abstract}

continuous hive weight/continuous hive temperature/bee colony phenology/adult bee mass/brood production

\section{INTRODUCTION}

Data gathered from bee colonies on a continuous basis, in this case defined as hourly or more often for periods exceeding 2 days, are rich in information about bee colony growth and activity (Buchmann and Thoenes 1990; Meikle and Holst 2014). For example, foraging activity, as shown by weight changes due to forager traffic, and foraging success, as shown by increases in hive food stores, can be measured, provided the scales are of sufficient precision (Meikle et al. 2008).

Electronic supplementary material The online version of this article (doi:10.1007/s13592-015-0370-1) contains supplementary material, which is available to authorized users.

Corresponding author: W. Meikle, william.meikle@ars.usda.gov Manuscript editor: Stan Schneider
Gates (1914) and Hambleton (1925) pioneered the use of continuous monitoring when they recorded weather effects on hive weight using mechanical scales. Buchmann and Thoenes (1990) advanced the field by using electronic scales linked to a computer and proposed using hive weight to examine the impact of pesticides on bee colonies, changes in nectar and pollen availability, and differences among honey bee races. Meikle et al. $(2006,2008)$ placed four hives on electronic scales to show the effects of rainfall and swarming on hive weight and divided the resulting continuous hive weight data into a $25-\mathrm{h}$ running average and a within-day detrended data (the difference between the running average and the raw data). Detrending to remove longer term trends in data is used in many disciplines in ecology and elsewhere; Garibaldi et al. (2011), for example, detrended leaf data in order to remove latitude effects. Meikle et al. (2008) correlated parameters of curves fit to running average and 
detrended data with adult bee mass, brood mass, and food stores gathered from hive inspections, demonstrating that the two types of data reveal different aspects of colony dynamics.

Our objective was to relate continuous weight and temperature data to the weights of adult bees and sealed brood. Meikle et al. (2008) associated within-day weight variability with forager activity and colony food consumption. However, the size of the forager population, during a nectar flow, may be a good indicator of the size of the adult bee population for hives that are otherwise similar in terms of health and age structure. Within-hive temperature regulation is to some extent demand-driven, in that larger amounts of brood require bees to maintain high temperatures over proportionally larger hive volumes, and our goal was to exploit that relationship. We collected continuous weight and temperature data from hives in two apiaries in southern Arizona in 2013 and 2014 and generated relationships between adult bee mass and weight variability, and between brood mass and temperature variability. We then fieldvalidated the relationships using independent datasets from California and France.

\section{MATERIALS AND METHODS}

The study had four main parts: (1) installation, maintenance, and evaluation of outdoor scales and withinhive temperature probes in Arizona; (2) calculation of surface area to mass relationships for brood and honey stores for analysis of hive frame photographs; (3) analysis of hive weight and temperature variability; and (4) field validation.

\subsection{Hive weight monitoring}

In April 2013, eight honey bee colonies were established from package bees (approx. $1.5 \mathrm{~kg}$ ) with Cordovan Italian queens (C.F. Koehnen \& Sons, Glenn, CA). The packages were installed in painted, ten-frame, wooden Langstroth deep boxes (43.65-1 capacity) fitted with migratory wooden lids (Mann Lake Ltd, Hackensack, MN). Four hives were installed near the Carl Hayden Bee Research Center (hereafter CHBRC) in Tucson, $\mathrm{AZ}$, and four hives were installed at an apiary near Red Rock, AZ, about $45 \mathrm{~km} \mathrm{NE}$ of CHBRC. On
11 September, Red Rock hives were relocated to the Santa Rita Experimental Range (hereafter SRER), about $56 \mathrm{~km}$ south of CHBRC. The CHBRC was more sheltered with access to diverse, managed gardens in urban Tucson while SRER was more exposed with foraging limited to native, unmanaged plants, particularly mesquite (Prosopis spp.). Each apiary was provided with a permanent water source and hives were spaced 1-3 m apart. Hives were supplied with sucrose syrup and supplemental pollen feed (bee pollen mixed with sucrose and water) as needed, and provided with a second deep box as the colonies expanded; weight changes associated with such hive management was removed from the data (see below). Densities of Varroa mites were monitored using sticky boards every 2-3 months and hives in both apiaries were treated with amitraz or thymol (Apivar and Apiguard, Véto-pharma, France).

On 25 June 2013, the CHBRC hives were placed on top of stainless steel electronic scales (TEKFA ${ }^{\circledR}$ model B-2418, Galten, Denmark) (max. capacity $100 \mathrm{~kg}$, precision $\pm 10 \mathrm{~g}$; operating temperature -30 to $70{ }^{\circ} \mathrm{C}$ ) powered by wall current and linked to 12-bit dataloggers (Hobo ${ }^{\mathbb{B}}$ U-12 External Channel datalogger, Onset Computer Corporation, Bourne, MA, USA). The weighing system had an overall precision of approximately \pm 20 g. In September 2013, the SRER hives were also placed on scales (same model as above) powered by solar panels (BP Solar model 1230, Mimeure, France) linked to dataloggers (same model as above). All hive parts (e.g., bottom boards, entrance reducers, hive bodies) were weighed using a portable electronic scale (precision $\pm 0.5 \mathrm{~g}$; OHaus model EC15, Parsippany, NJ, USA).

All hives kept on scales were evaluated periodically to determine the weights of the adult bee and sealed brood populations and of food stores (see Figure 1). At each evaluation, all frames were gently shaken to dislodge adult bees, individually weighed on an electronic scale, photographed using a 16.3 megapixel digital camera (Pentax K-01, Ricoh Imaging Co., Ltd.) and then replaced in the hive. Evaluations took place approximately every 4 weeks between 28 July and 18 November 2013, and between 12 February and 7 May 2014 at CHBRC, and between 18 September and 15 November 2013, and on 11 March and 3 April 2014 at SRER. 


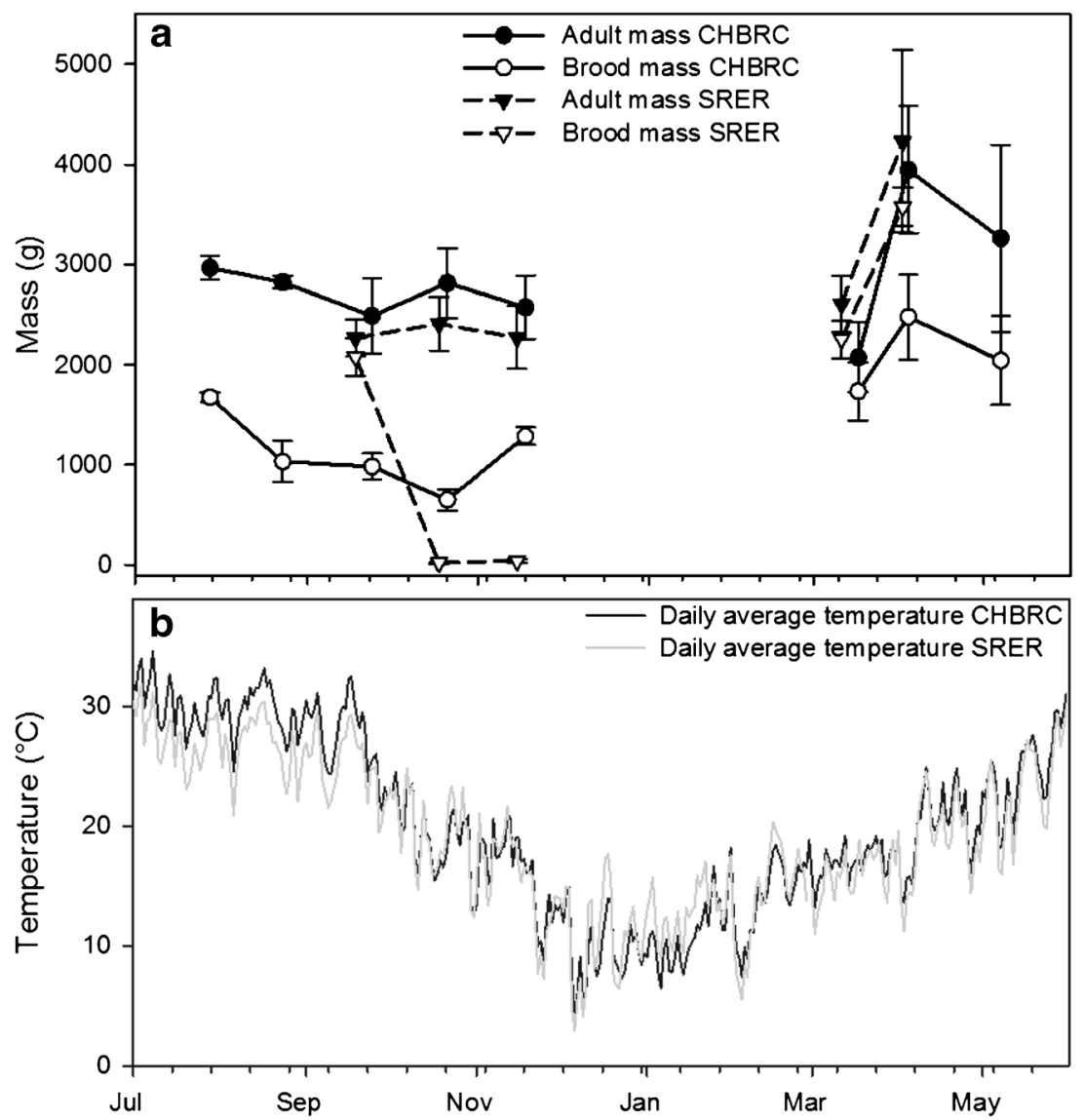

Figure 1. Average total adult bee masses and brood masses per honey bee colony for apiaries at CHBRC and SRER in southern Arizona ( $N=4$ per site). a Total adult bee mass and brood mass per colony over time (bars show S.E.); b Average daily temperature at each of the sites during the course of the study.

\subsection{Hive temperature monitoring}

This section consists of two parts: (1) determining a suitable position for a temperature sensor within a hive and (2) monitoring temperature in hives over time using sensors placed in that position. On 1 July 2013, temperature probes (TMC6-HD, Onset Computer Corp.) were placed at four positions within each of three hives at CHBRC: (1) at the center of the lower box between frames 5 and 6 ; (2) between the last frame and the brood box wall on the northernmost side; (3) on top of frames 5 and 6 in the lower box; and (4) on top of frames 5 and 6 in the upper box. The probes consist of a 2-m-long, 5mm-thick thermocouple cable attached to a $17 \times 55 \times 68 \mathrm{~mm}$ datalogger, which was placed between the hive box and the outside frame on the north side. Temperature data were gathered every $15 \mathrm{~min}$ for
17 days. The experiment was repeated 4-18 November using four hives. Exterior (ambient) temperature data were obtained for these time periods from a University of Arizona weather database (http://ag.arizona.edu/ azmet/01.htm) from a weather station $<2 \mathrm{~km}$ away. Temperature data were averaged across hives for each sensor position and correlation coefficients were calculated for all pairwise combinations among sensor positions (positions 1-4 within the hive and exterior temperature), resulting in ten comparisons for each time period.

Internal hive temperature was also monitored in each of the hives kept on scales at CHBRC and SRER described in Sect. 2.1. Two temperature probes were placed in each of the hives installed on the electronic scales at positions 2 and 3 described above on 28 August at CHBRC and on 19 September at SRER. Probes were removed for the winter on 3 December at 
CHBRC and 18 November at SRER. The hives were left undisturbed for the coldest months. On 11 February, integrated temperature sensors (iButton Hygrochron and Thermochron, Maxim Integrated, San Jose, CA, USA), $5 \mathrm{~mm}$ thick and $17 \mathrm{~mm}$ in diameter, were placed in $30 \times 40-\mathrm{mm}$ vinyl mesh bags and stapled onto frames at each position.

\subsection{Estimating surface area to weight relationships for brood and food stores}

Weights of brood and food stores were estimated using the method described by Meikle et al. (2006) (see Online Resource 1). Standard capped honey surface density in $\mathrm{g} / \mathrm{cm}^{2}$ was estimated from 36 frames containing only capped honey and obtained from hives in the same apiary and started from packages at the same time as those described in Sect. 2.1. Capped honey surface area was estimated from the frame photographs using ImageJ version 1.47 image analysis software (W. Rasband, National Institutes of Health, USA). The mean weight of a frame of drawn comb, estimated from a sample of 34 frames of empty drawn comb, was subtracted from the capped honey frame weights and linearly regressed on the capped honey surface area in $\mathrm{cm}^{2}$ (Proc Reg, SAS Institute, 2002). The line was forced through the origin to generate a predictive equation, and the resulting slope used to estimate capped honey surface density. The same procedure was used to estimate uncapped honey (nectar) surface density, using 27 frames.

To determine standard brood surface density in $\mathrm{g} / \mathrm{cm}^{2}, 100$ frames obtained from hives outside the study with at least $5 \%$ brood by surface area and with little or no honey stores were weighed and the average weight of a frame of drawn comb subtracted from each of those weights. For each frame, the surface areas of brood and of any capped or uncapped honey was measured, and weights of the drawn comb and capped and uncapped honey were subtracted. The remaining weight was attributed to the brood mass and used to estimate brood surface density. For experimental frames containing both brood and food stores, brood weight was calculated first and remaining weight attributed to food stores. Pollen was not measured separately, owing to its variable appearance and scattered distribution, and this method would attribute pollen weight to food store weight. The weights of eggs and uncapped larvae were likewise not estimated because of their low mass (eggs weigh 0.12 to $0.22 \mathrm{mg}$ (Taber and Roberts 1963)) and the difficulty in identifying them reliably in photographs taken in field situations; the error was assumed to be negligible. To convert brood mass to individual larvae, comb cells per $\mathrm{cm}^{2}$ was estimated from 30 frames of drawn comb taken from several hives at the CHBRC and SRER apiaries.

\subsection{Data analysis}

Weights of adult bee and sealed brood (hereafter "brood") weights per colony were compared between CHBRC and SRER sites using repeated measures ANOVA (Proc Mixed, SAS Inc. 2002) for sampling occasions in September, October, and November in 2013 and March and April 2014. Brood and adult population weights were log-transformed prior to analysis. Degrees of freedom were calculated using the Satterthwaite method, and residual plots were assessed visually for variance homogeneity. Post hoc contrasts of the least squares mean differences were conducted for significant factors, using the Bonferroni adjustment for the $t$-value probability. To compare the sites with respect to food availability, a similar analysis was conducted for changes in food stores between each of the sampling occasions.

Hive weights were recorded every $15 \mathrm{~min}$ in each apiary. Weight changes due to hive management, such as hive inspection or feeding, were removed from the data. Raw weight data were averaged to produce hourly weight estimates from 4 July to 18 November at CHBRC, and from 28 August to 15 November at RR and SRER, with some pauses in the data (due to hive management issues). Weight data were divided into two components: the running average and detrended weights. The running average weight was calculated by averaging the hive weight over the preceding $12 \mathrm{~h}$, the hour in question, and the following $12 \mathrm{~h}$ (for a total of $25 \mathrm{~h}$ ), and the detrended weight was calculated by subtracting the running average weight for a given hour from the raw data for that hour:

$W_{0}-\frac{1}{25} \sum_{h=-12}^{+12} W_{h}=D_{0}$

where $W_{h}$ is the raw weight in $\mathrm{g}$ at a given hour, $h$, before and after the hour of interest, $h=0$, and $D_{0}$ is the detrended datum at that hour. This method separates short-term $(<25 \mathrm{~h})$ weight 
Table I. Average standard values for various hive components.

\begin{tabular}{llll}
\hline Item & $N$ & Parameter & Mean value $( \pm$ SE $)$ \\
\hline $\begin{array}{l}\text { 1. Wooden Langstroth frames } \\
\text { with plastic foundation }\end{array}$ & 60 & Interior surface area & $880.26( \pm 0.31) \mathrm{cm}^{2} / \mathrm{side}$ \\
& & Weight & $381.52( \pm 1.25) \mathrm{g} / \mathrm{frame}$ \\
2. Frames with drawn comb & 34 & Weight & $555.46( \pm 8.86) \mathrm{g} / \mathrm{frame}$ \\
3. Capped honey & 36 & Surface area density & $1.43 \mathrm{~g} / \mathrm{cm}^{2}$ \\
4. Uncapped honey & 27 & Surface area density & $1.10 \mathrm{~g} / \mathrm{cm}^{2}$ \\
5. Capped brood & 100 & Surface area density & $0.77 \mathrm{~g} / \mathrm{cm}^{2}$ \\
6. Comb cell density & 30 & Cell density & $4.02( \pm 0.07) \mathrm{cells}^{2} / \mathrm{cm}^{2}$ \\
\hline
\end{tabular}

$N$ number of frames used to make the determination

changes, such as those due to daily bee activity, from long-term $(\geq 25 \mathrm{~h}$ ) changes, such as those due to honey production and bee population growth.

To model hourly detrended weights, a sine function was fit to the data by examining all possible combinations of amplitude (range $1-1000 \mathrm{~g}$ at $1 \mathrm{~g}$ increments), period (range $1-30 \mathrm{~h}$ at $1 \mathrm{~h}$ increments), and phase (range 0-6.3 at 0.1 increments), choosing the optimal combination using least sums-of-squares, and calculating the explained variance $\left(r^{2}\right)$. Meikle et al. (2008) used $168 \mathrm{~h}$ (7 days) data subsets per analysis. We compared the amplitudes, periods, and $r^{2}$ for curves fit to 24,72 , and $168 \mathrm{~h}$ subsets. The subset for a given day started at 1:00 a.m. and lasted until midnight while the window of data used included 1,3, or 7 days in which the day of interest was the middle day. Adult bee mass data obtained from hive evaluations were regressed on the detrended sine amplitudes averaged across the 7 days prior to that evaluation (Sect. 2.1), and that relationship was validated using independent datasets (see Online Resource 2).

Temperature data was processed and modeled in the same way as weight data: 25 -h running averages were subtracted from raw data to produce detrended data, and then, sine curves fit to that detrended data using 3 days subsets. In order to identify sensor positions that did

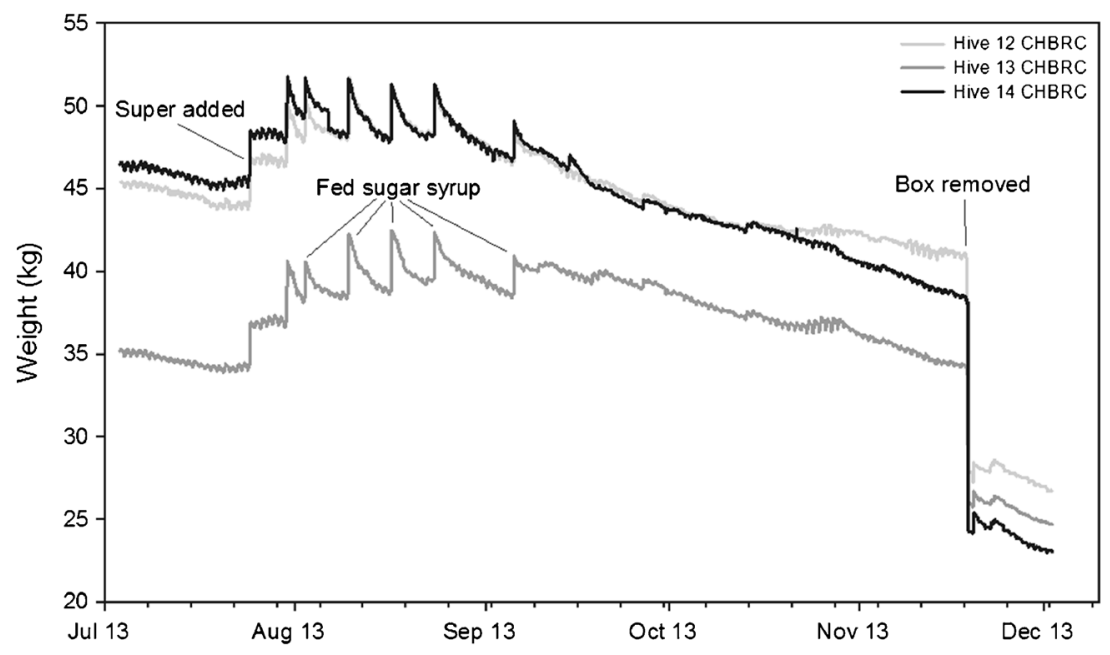

Figure 2. A sample of continuous weight data and management events for three bee hives at CHBRC in southern Arizona in fall 2013. The labels describe management events. 
provide information on colony temperature regulation but did not interfere with bee movement, the four sensor locations were compared within the July and November time periods with respect to the daily average temperature and to amplitude using repeated measures ANOVA (Proc Mixed SAS Institute, 2002). A correlation matrix was then calculated for exterior sensor positions and within-hive sensor positions averaged across hives. Weekly average sine wave amplitudes from temperature sensors were regressed on brood mass data obtained from hive evaluations (Sect. 2.1), and that relationship was validated using independent datasets (see Online Resource 2).

\section{RESULTS}

\subsection{Hive weight data}

Standard weight and surface density values are provided for colony parts (Table I). The regression
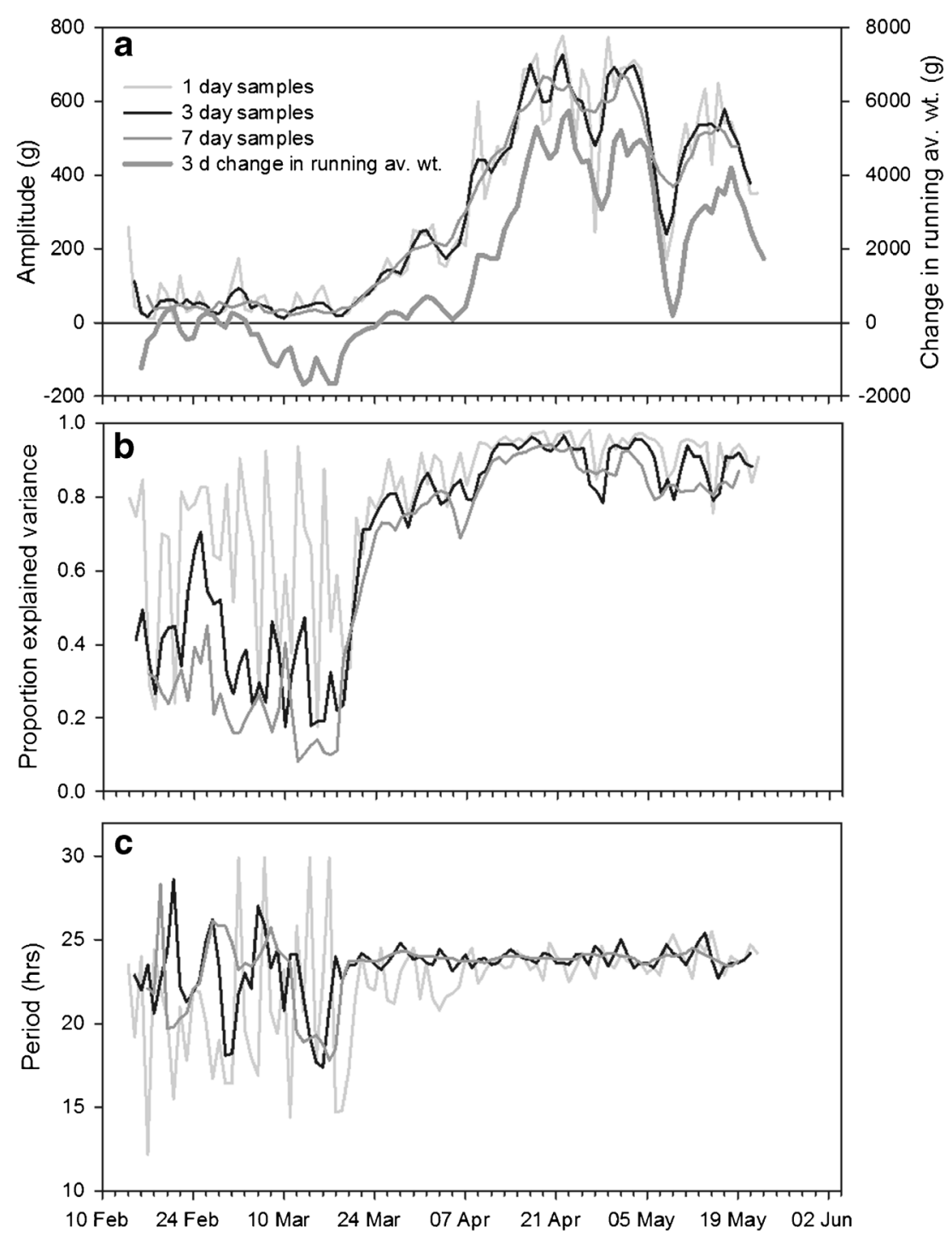

Figure 3. Amplitudes, $r^{2}$ (amount of explained variance), and periods for sine curves fit to continuous detrended weight data for a bee hive (hive 12) at CHBRC in southern Arizona. Sine curves were fit to 1-, 3-, and 7-day subsets of the same detrended weight data for comparisons of subset size. a Amplitudes; $\mathbf{b} r^{2}$ values; $\mathbf{c}$ periods. 
of capped honey mass on surface area was significant (adj. $r^{2}=0.93, F_{1,36}=508.28, P<0.0001$ ). Given that cell depth in a typical Langstroth frame is about $1 \mathrm{~cm}$, the density of capped honey as calculated here was about 1.3-1.4 g/ml. Regression equations for surface densities of uncapped honey and brood were also significant (uncapped honey adj. $r^{2}=0.90, F_{1,26}=255.78$, $P<0.0001$; brood: adj. $r^{2}=0.78, F_{1,99}=349.08$, $P<0.0001)$. Brood surface density, $0.77 \mathrm{~g} / \mathrm{cm}^{2}$, was similar to that reported for colonies in France (0.72 $\left.\mathrm{g} / \mathrm{cm}^{2}\right)$ (Meikle et al. 2008). Average comb cells per $\mathrm{cm}^{2}$ was 4.02 , so the average brood cell weight was $0.19 \mathrm{~g}$. CHBRC hives had Varroa mite falls of 29.4 mites/day on average, ranging as high at 116.9 mites/day in June 2014, and they were treated with Amitraz in November 2013, and thymol in June and October 2014. SRER hives had mite falls of 24.2 mites/day on average, ranging as high as 101.9 mites/day in August 2014, and they were treated with Amitraz ${ }^{\circledR}$ in November 2013 and August 2014. We assumed that the impact was equal among hives.

Average total adult bee mass per colony were not significantly different with respect to location $(P=0.18)$, date $(P=0.11)$, or location $\times$ date interaction $(P=0.83)$ (Figure 1). However, average total brood mass per colony did differ significantly with respect to location $\left(F_{1,26}=19.85\right.$,
$P<0.0001)$, date $\left(F_{4,26}=22.42, P<0.0001\right)$, and their interaction $\left(F_{4,26}=14.70, P<0.0001\right)$. Changes in colony food stores also differed significantly with respect to location $\left(F_{1,16}=64.17\right.$, $P<0.0001)$, date $\left(F_{2,16}=69.44, P<0.0001\right)$, and their interaction $\left(F_{2,16}=42.73, P<0.0001\right)$.

A sample of the raw weight data for fall 2013 at CHBRC is shown (Figure 2). The scale for one hive (hive 11) at CHBRC acted unpredictably in September and October so the associated continuous weight data were excluded. One colony at SRER died in late winter 2014 and was excluded from the 2014 analysis. Sine curves fit to 1, 3, and 7 day subsets differed over time with respect to changes in amplitude, $r^{2}$, and to period (Figure 3). Running average weight data were included on the amplitude figure and showed that amplitude values anticipated the increase in hive weight due to foraging. An adult bee kill was observed on September 16, 2013, in one hive at the CHBRC apiary; the raw and amplitude data were compared with data from a neighboring unaffected hive and with published data from a swarming event (see Online Resource 3).

Average detrended amplitude was correlated with average adult bee mass per hive within sampling occasion $\left(F_{1,10}=50.24\right.$, adj. $r^{2}=0.817$, $P<0.0001$ ) (Figure 4). Upon closer examination, detrended data outside nectar flows tended to have poorer curve fits, more variable periods and lower amplitudes than data during nectar flows (Meikle

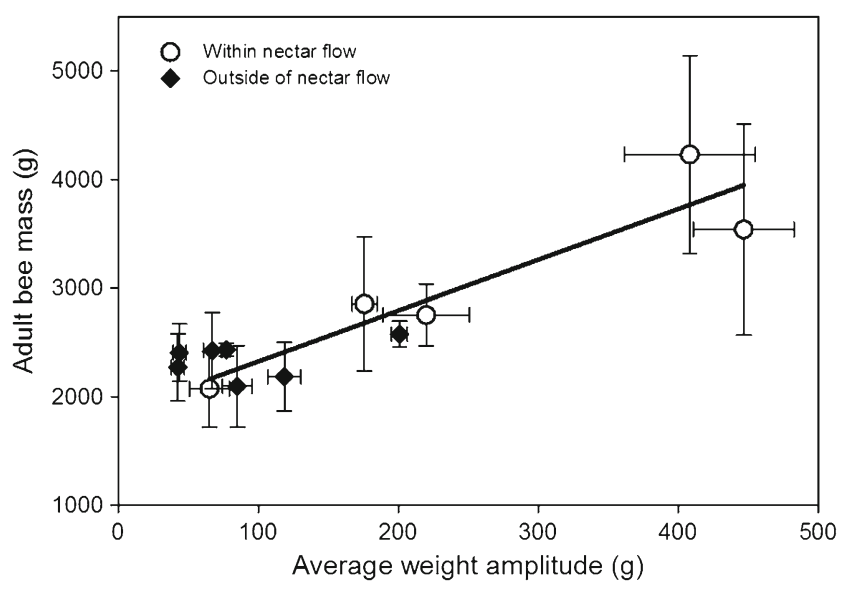

Figure 4. Average estimated per colony adult bee mass per apiary regressed on average detrended weight amplitude per apiary for honey bee colonies in southern Arizona. Bars show \pm S.E. Each point is the average value of 3 (CHBRC) or 4 (SRER) bee hives on a particular sampling occasion. 
et al. 2008) with nectar flows being identified as extended ( $>7$ days) periods of monotonic increases in running average hive weight. Using that definition, all evaluations conducted in March, April, and May $2014(N=5)$ occurred during nectar flows, and those conducted in July through November 2013 $(N=7)$ occurred outside nectar flows. The regression of total adult mass on detrended amplitude during nectar flows was significant $\left(F_{1,3}=15.619\right.$, adj. $\left.r^{2}=0.785, P=0.029\right)$. The resulting regression equation within a nectar flow was

Adult bee mass $=1857+4.686^{\circ} W_{a}, \quad$ (2) where $W_{a}$ is average detrended weight amplitude in grams. The regression for data collected outside of nectar flows was not significant $(P=0.420)$. We used data from the France trial to validate this approach. Raw continuous weight data showed a nectar flow in July and the beginning of August 2005 (see Meikle et al. 2008). The linear relationship shown in Eq. 2 was used to calculate the expected bee mass, and these data were compared to the observed bee mass (Figure 8). The predicted/observed ratio ranged from 0.90 to 1.38 for evaluations done on 20 July and 0.92 to 1.31 for evaluations done on 3 August.
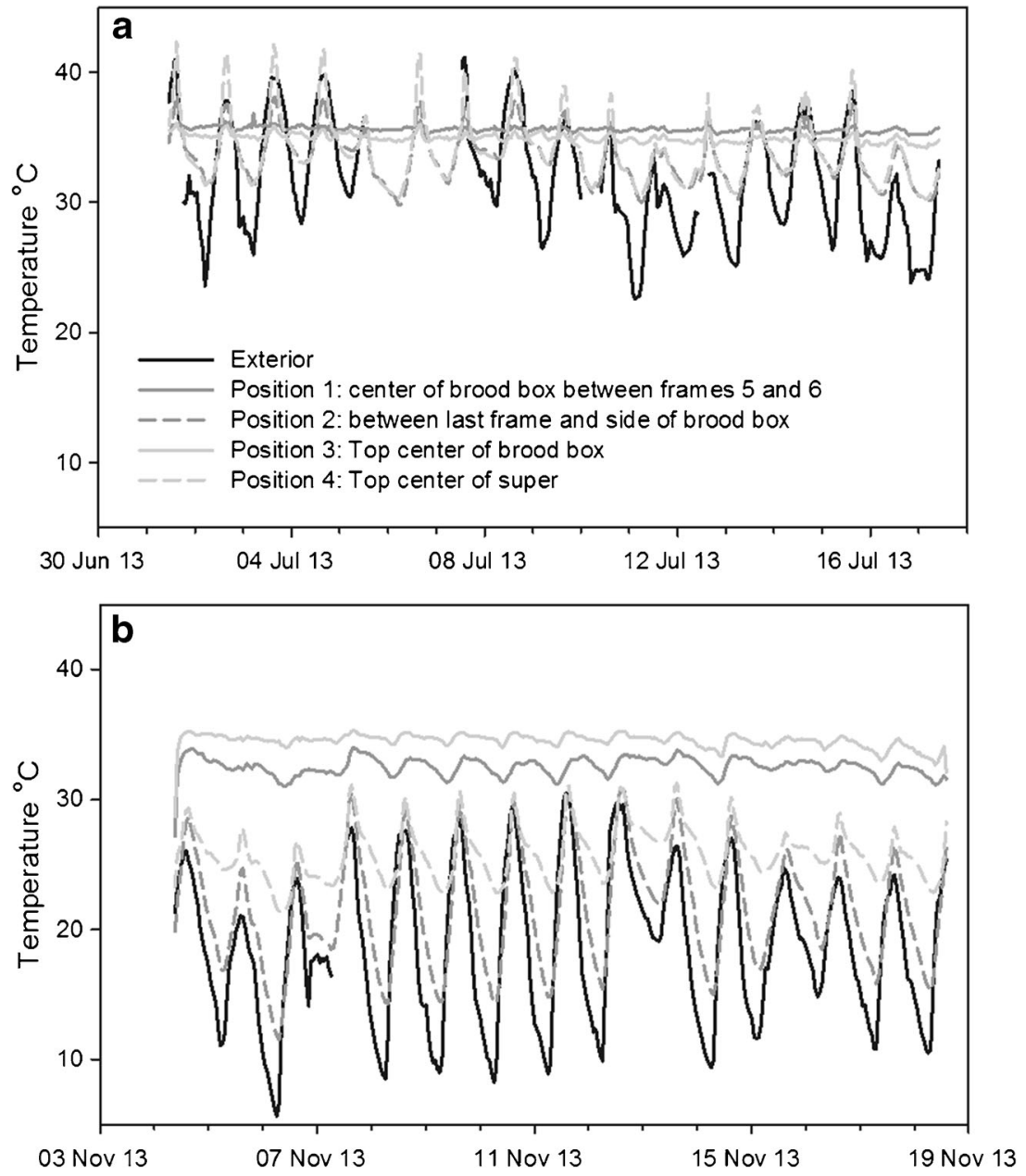

Figure 5. Average data for temperature sensors placed at four locations within bee hives, compared to exterior temperature data, in southern Arizona. a Data for three hives in July 2013; b data for four hives in November 2013. 


\subsection{Hive temperature data}

Sensor position was evaluated with respect to (1) amplitude of sine curves fit to the detrended temperature data and (2) average daily temperature. In both July and November, sensor position had a significant effect on daily temperature values (July: $F_{3,20}=26.55 ; P<0.0001$; November: $\left.F_{3,21}=86.71, P<0.0001\right)$ as well as on detrended amplitudes (July: $F_{3,7}=37.91$; $P<0.0001$; November: $F_{3,16}=54.62, P<0.0001$ ). Post hoc contrasts for both months and in both cases showed that only positions 1 and 3 were not significantly different from each other (Figure 5).

Temperature sensor position data profiles were evaluated with respect to exterior conditions by comparing the correlation coefficients among the different positions within time period (Table II). All correlation coefficients were significant with 384 values per position in July and 342 values per position in November ( $P$ always $<0.0001$ for all comparisons). However, correlation magnitudes were very different. For both datasets, ambient temperature was most correlated with positions 2 and 4, and least correlated with positions 1 and 3, while positions 1 and 3 were themselves highly correlated. Data obtained from positions 1 and 3 were very similar; but position 3 was less intrusive, since it was on top of the frames rather than the center where it may interfere with bee movement and brood rearing so that position was selected as the standard sensor position.

As with detrended weight data, sine curves were fit to 1-, 3-, and 7-day detrended temperature data subsets; an example showing amplitude, $r^{2}$, and period for the different subset sizes are shown (Figure 6). With respect to this hive, detrended amplitudes increased as the running average temperature decreased from September to December, indicating reduced temperature control, while the $r^{2}$ increased and the sine period values stabilized at about $24 \mathrm{~h}$, indicating increased influence of exterior temperature. Brood production decreased: by 19 October, the hive in this example had $<40 \mathrm{~g}$ brood.

Average temperature amplitude was inversely correlated with brood mass $\left(F_{1,6}=51.24\right.$, adj. $\left.r^{2}=0.652, P=0.0052\right)$ although not with adult bee mass $(P=0.150)$. Visual inspection of the data indicated that log transformation might improve the regression fit. Transformation had no effect with respect to adult bee masses $(P=0.152)$, but the relationship with brood mass was substantially improved $\left(F_{1,7}=161.114\right.$, adj. $r^{2}=0.952$, $P<0.0001$ ) (Figure 7). The regression equation was as follows:

$$
\text { Log brood mass }=4.122-0.0134 \cdot T_{a}
$$

where $T_{a}$ is average temperature amplitude in units of $0.01{ }^{\circ} \mathrm{C}$. This relationship was validated

Table II. Correlations among different locations for temperature probes within hives in July and November 2013.

\begin{tabular}{llllll}
\hline & & Position 1 & Position 2 & Position 3 & Position 4 \\
\hline July 2013 & Ambient & 0.281 & 0.938 & 0.542 & 0.903 \\
& Position 1 & & 0.400 & 0.769 & 0.457 \\
& Position 2 & & & 0.708 & 0.967 \\
& Position 3 & & & & 0.704 \\
November 2013 & Ambient & 0.332 & 0.948 & 0.365 & 0.765 \\
& Position 1 & & 0.532 & 0.747 & 0.718 \\
& Position 2 & & & 0.461 & 0.911 \\
& Position 3 & & & & 0.533
\end{tabular}

Each hive had two boxes. Position 1: center of the lower box between middle frames; position 2: between the last frame and the wall of the lower box on the northernmost side; position 3: on top of the middle frames in the lower box; position 4: on top of the middle frames in the upper box 

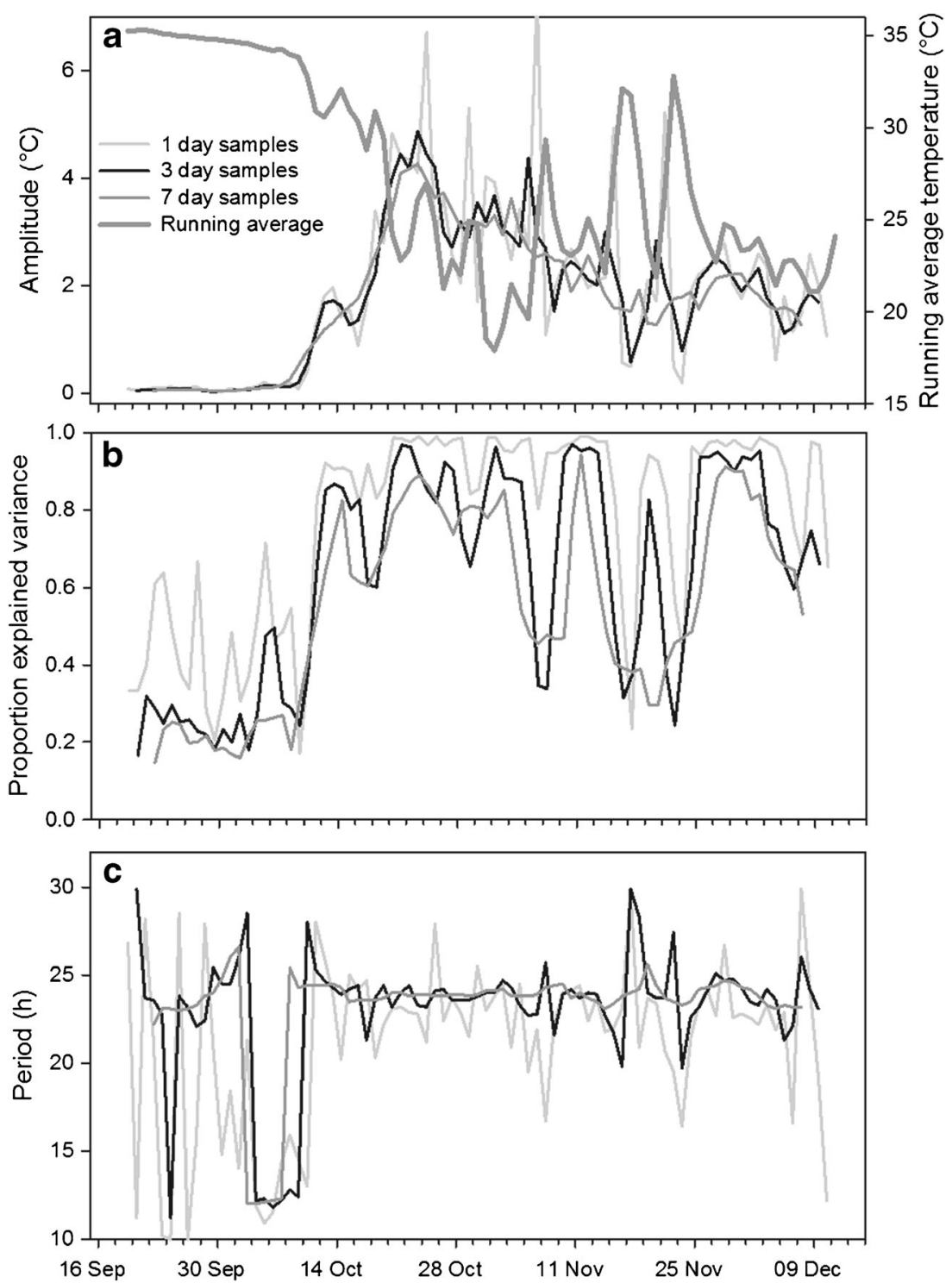

Figure 6. Amplitudes, $r^{2}$ (amount of explained variance), and periods for sine curves fit to continuous detrended temperature data for a bee hive (hive 12) at CHBRC in southern Arizona. Sine curves were fit to 1-, 3-, and 7-day subsets of the same detrended temperature data for comparisons of subset size. a Amplitudes; $\mathbf{b} r^{2}$ values; c periods.

using data from the hive evaluations conducted in May and August on bee hives in California (see Online Resource 2). Hourly temperature data showed a sharp increase in average hive temperature and reduced temperature variability at the end of March, when pollen traps were removed and hives were moved to the new orchard (Figure 8).
Only three hives were still alive by 20 August; the high rate of colony loss was attributed to lack of forage due to drought.

Continuous amplitude data for both weight and temperature measurements at both apiaries over time showed that colony phenology was very different depending on location (Figure 9). Bee 


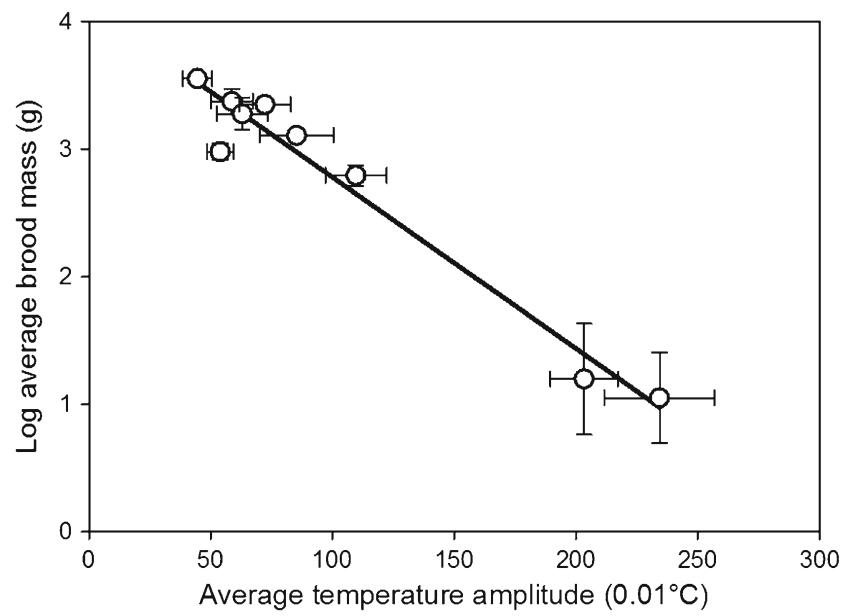

Figure 7. Average log total brood mass per apiary regressed on average detrended temperature amplitude per apiary for honey bee colonies in southern Arizona. Bars show \pm S.E. Each point is the average value of 3 (CHBRC) or 4 (SRER) bee hives on a particular sampling occasion.

colonies at CHBRC had substantial quantities of brood throughout the study, as shown by the low temperature amplitudes, while colonies at SRER had little or no brood in October and November, 2013, as reflected in higher amplitudes. The lowweight amplitudes in both locations in 2013 showed comparatively little foraging effort but the spike in both locations in 2014 reflected strong local nectar flows.

\section{DISCUSSION}

Here, we described relationships in continuous weight and temperature data that pertain to bee colony parameters using data from two apiaries in southern Arizona that were significantly different in terms of colony phenology, and we validated the approach using independent datasets from France (2005) and California (2014). Meikle et al. (2008) showed that detrended weight amplitudes increased during nectar flows due to increased foraging (as shown by increases in the running average hive weight) and decreased sharply when the adult bee population was reduced due to swarming. In this study, similar decreases in detrended weight amplitudes in were observed with respect to foraging and for another kind of event, an acute adult bee kill. The swarming and adult bee kill events had distinctly different patterns in the raw weight data.

To analyze detrended hourly weight data, Meikle et al. (2008) fit sine curves using 7-day (168 h) subsets. Such large subsets provide robust results, but because values represent weekly averages, shorter-term changes can be lost. In addition, the initial and final 3 days of data are necessarily lost from each uninterrupted dataset. Data subsets of 1 day provide high sensitivity and allow more usable data, but parameters such as $r^{2}$ and period become less stable and sensitive to singular events such as high wind or rain. Data subsets of 3 days appeared to provide a compromise between reasonably stable parameter estimates, and higher sensitivity and more usable data compared to 7-day subsets. Detrended weight amplitudes of 3-day subsets correlated well with total adult bee mass within nectar flows, with predicted values between 90 and $130 \%$ of observed values from an independent dataset.

Similar methods were applied to continuous temperature data. Bees maintain a brood cluster temperature close to $35^{\circ} \mathrm{C}$ for brood development (Jones et al. 2004), so we expected temperature variability, in the form of detrended amplitudes, to be lower in the presence of brood and higher in the absence of brood. We first had to determine an appropriate sensor position, since every point 

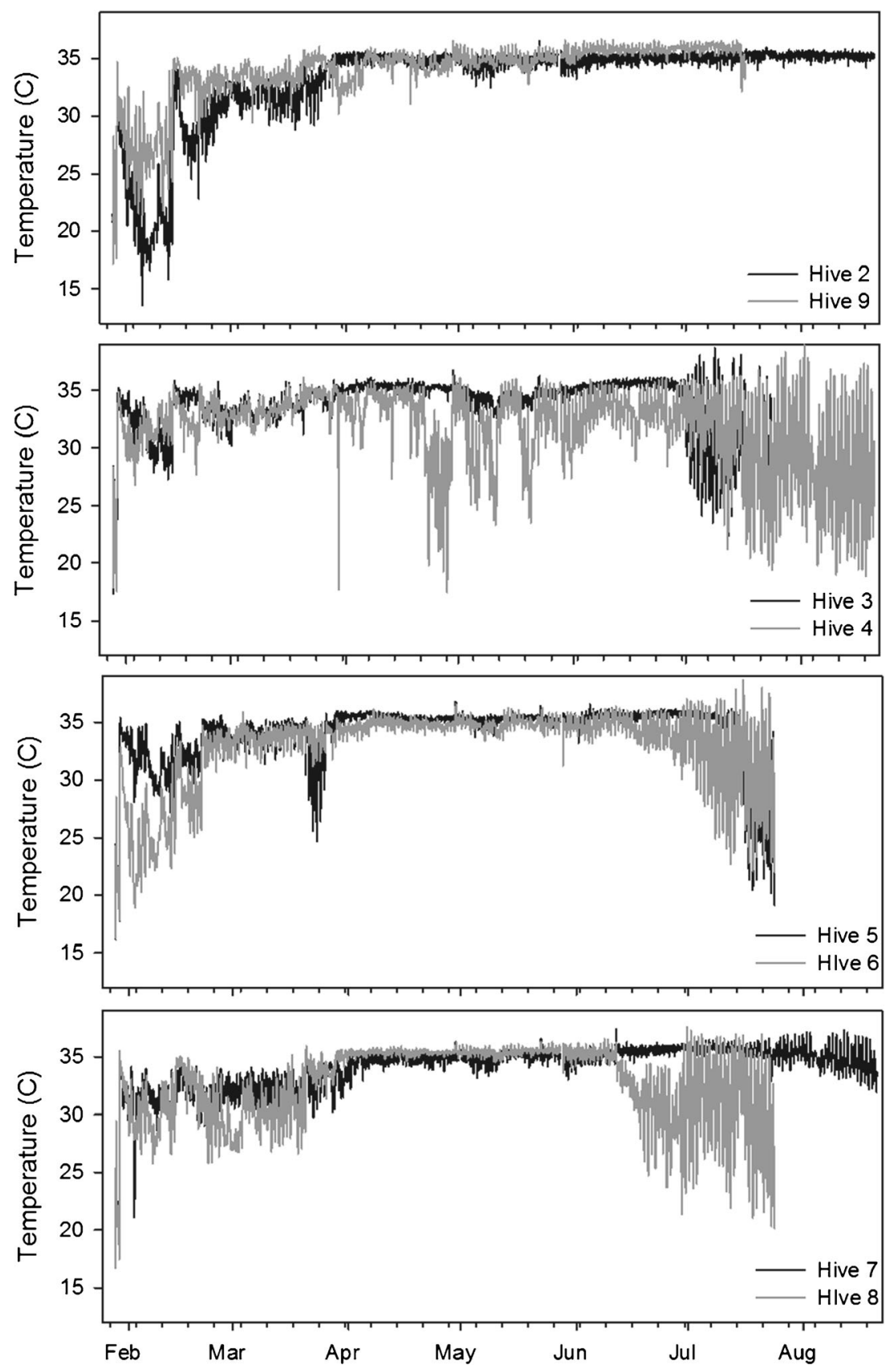

Figure 8. Hourly temperature data for the interior of eight bee hives kept near Fresno, CA, from January 21 to August 18, 2014.

within the hive can be considered to have its own temperature profile. We assumed that each such profile would be a function of two mutually exclusive factors: exterior temperature and colony-generated temperature. By placing sensors at different fixed points within the hive and taking 

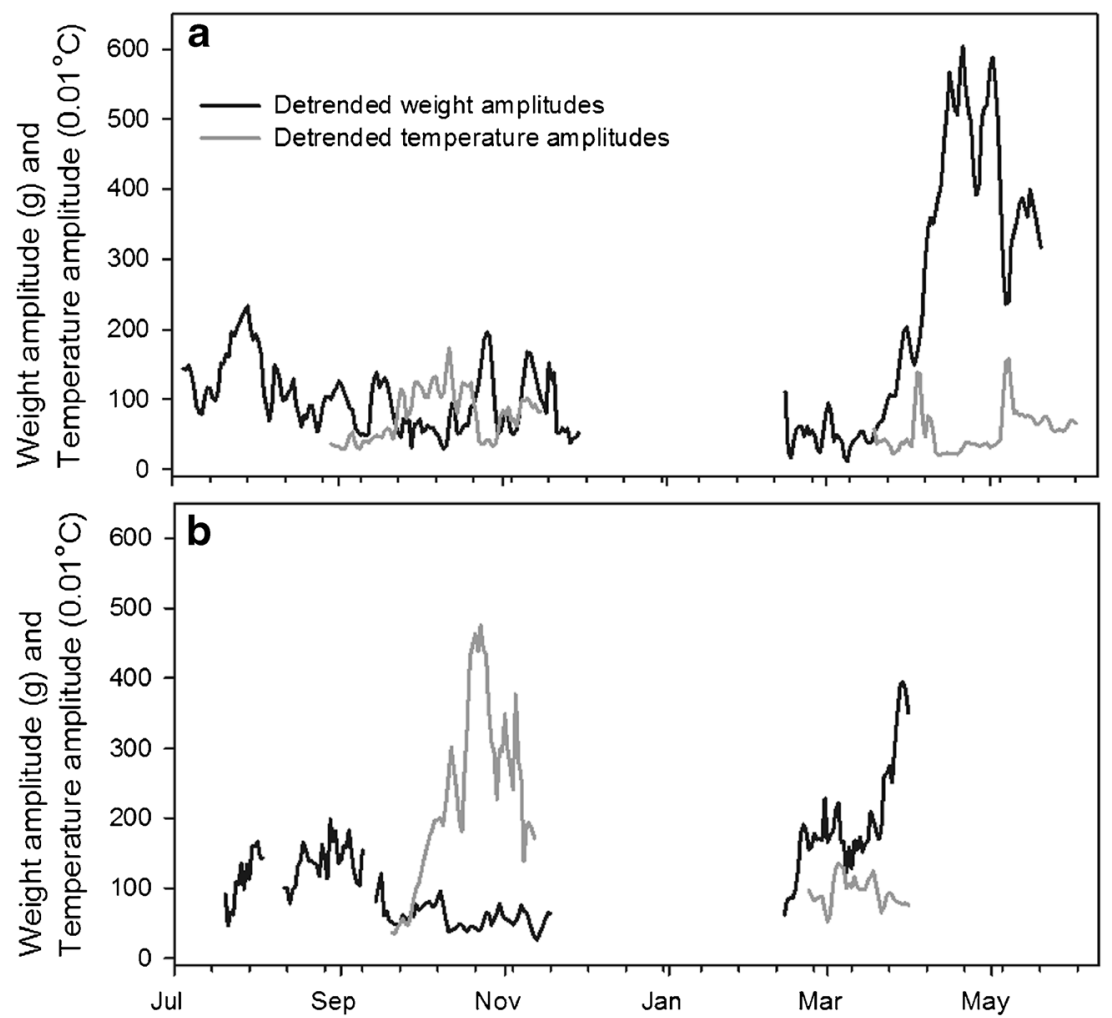

Figure 9. Amplitude data for continuous weight and temperature data for two apiaries in southern Arizona. a CHBRC apiary (three hives); b SRER apiary (four hives).

into account the need to avoid interfering with bee movement and brood rearing, we found that a sensor placed on top of the middle frames of the brood boxes (position 3 in our study) would provide information about the colony while causing little or no interference.

We observed that brood mass, rather than just presence, was inversely related to amplitude, probably due to (1) the localized nature of temperature management behavior within the colony and (2) the changing size and location of the brood mass (Szabo 1989) relative to the position of the sensor. Because the sensor was at a fixed point, the distance between the sensor and the brood cluster surface varied as the cluster expanded and retracted during the year, which was reflected in the data. As Szabo (1989) showed, clusters can move, but in general not far from the center of the box. Log transformation of the brood mass resulted in an improved curve fit $\left(r^{2}>95 \%\right)$. The logarithmic nature of the relationship probably resulted from one or more factors. Considering the brood cluster as a roughly spherical volume at a high temperature, the volume of the "shell" of air surrounding that brood cluster would increase as a cube of the distance of the cluster to the sensor; that dilution effect, combined with the low thermal conductivity of humid air (Tsilingiris 2008), could cause the temperature gradient over that distance to be nonlinear. Field validation showed predicted values were close to observed values. Management practices or equipment that differ substantially from those used here may affect the relationship.

These results support the idea that researchers and interested beekeepers can monitor honey bee colony brood production and adult bee mass, as well as events such as an acute pesticide effect and swarming, without excessive disturbance. However, further validation of these approaches 
is still needed. Application of the detrended weight amplitude relationship across different geographical areas assumes, for example, that foragers constitute about the same proportion of the adult bee population across those areas during a nectar flow, whereas factors that affect bee behavior, such as bee genetic stock, pesticide exposure, or bee nutritional status may alter that proportion. Future work will focus on quantifying the effects of such factors on continuous weight and temperature data, in addition to examining shortterm patterns in raw data for clues to colony behavior.

\section{ACKNOWLEDGMENTS}

Many people provided time and access to hives, apiary sites, and equipment, among the most important being M. Heitlinger at the Santa Rita Experimental Range and M. Mcclaran at the University of Arizona; A. Lawson and A. Novicki at California State University, Fresno, CA; Olam International (almond orchards); Hiatt Honey Company; and C. Ledbetter and J. Throne at the San Joaquin Valley Agricultural Sciences Center, USDA-ARS, Parlier, CA. Technical assistance by M. Giansiracusa was most helpful. N. Holst, V. Dietemann, and two anonymous reviewers greatly improved the manuscript.

OPEN ACCESS This article is distributed under the terms of the Creative Commons Attribution 4.0 International License (http://creativecommons.org/licenses/ by/4.0/), which permits unrestricted use, distribution, and reproduction in any medium, provided you give appropriate credit to the original author(s) and the source, provide a link to the Creative Commons license, and indicate if changes were made.

Contrôle de la phénologie de la colonie par l'utilisation de la variabilité intrajournalière du poids et de la température des ruches d'abeilles mesurés en continu

poids de la ruche / température / mesure en continu / phénologie / poids des adultes / production du couvain
Erfassung der Bienenvolk-Phänologie über die Tagesvariabilität von Gewichts- und Temperaturverlauf in Honigbienenvölkern

Kontinuierliches Bienenvolkgewicht / kontinuierliche Stocktemperatur / Bienenvolk-Phänologie / adulte Bienenmasse / Brutproduktion

\section{REFERENCES}

Buchmann, S.L., Thoenes, S.C. (1990) The electronic scale honey bee colony as a management and research tool. Bee Sci. 1, 40-47

Garibaldi, L.A., Kitzberger, T., Ruggiero, A. (2011) Latitudinal decrease in folivory within Nothofagus pumilio forests: dual effect of climate on insect density and leaf traits? Global Ecol. Biogeogr. 20, 609-619

Gates, B.N. (1914) The temperature of the bee colony, United States Department of Agriculture, Dept. Bull. No. 96

Hambleton, J.I. (1925) The effect of weather upon the change in weight of a colony of bees during the honey flow, United States Department of Agriculture, Dept. Bull. No. 1339

Jones, J.C., Myerscough, M.R., Graham, S., Oldroyd, B.P. (2004) Honey bee nest thermoregulation: diversity promotes stability. Science 305, 402-404

Meikle, W.G., Holst, N. (2014) Application of continuous monitoring of honey bee colonies. Apidologie 46, 1022

Meikle, W.G., Holst, N., Mercadier, G., Derouané, F., James, R.R. (2006) Using balances linked to dataloggers to monitor honeybee colonies. J. Apic. Res. 45 (1), 39-41

Meikle, W.G., Rector, B.G., Mercadier, G., Holst, N. (2008) Within-day variation in continuous hive weight data as a measure of honey bee colony activity. Apidologie 39, 694-707

Szabo, T.I. (1989) Thermology of wintering honey-bee colonies in 4-colony packs. Am. Bee J. 189, 554-555

Taber, S., Roberts, W.C. (1963) Egg weight variability and its inheritance in the honey bee. Ann. Entomol. Soc. Am. 56, 473-476

Tsilingiris, P.T. (2008) Thermophysical and transport properties of humid air at temperature range between 0 and $100^{\circ} \mathrm{C}$. Energy Convers. Manag. 49, 1098-1110 